\title{
The Effect of Text Summarization as a Cognitive Strategy on the Achievement of Male and Female Language Learners' Reading \\ Comprehension
}

\author{
Iraj Khoshnevis \\ Dept. of ELT, Ardabil Branch, Islamic Azad University, Ardabil, Iran \\ Ardabil, Iran \\ Tel: +98453-372-8022Ｅ-mail: sorour_parvinnejad@yahoo.com

\section{Sorour Parvinnejad (Corresponding author)} \\ Dept. of ELT, Ardabil Branch, Islamic Azad University, Ardabil, Iran \\ Ardabil, Iran \\ Tel: +98911-195-4462Ｅ-mail: sorour_parvinnejad@yahoo.com
}

Doi:10.5296/ ijld.v5i3.8271 URL: http://dx.doi.org/10.5296/ ijld.v5i3.8271

\begin{abstract}
This study aims at investigating the effect of teaching the summarization of text as a cognitive strategy on achievement of male and female students' reading comprehension. 60 English undergraduates studying at the University of Tonekabon participated in this study. The participants were randomly assigned into the experimental and control groups. A series of treatment were provided for the participants in the experimental group. Two reading comprehension tests, as the pretest and posttest, were given to the students of both groups to observe their reading comprehension ability at the beginning and at the end of the treatment sessions. A Two-way ANOVA was run on the obtained data. The results revealed that the instruction of summarization strategy had a significant effect on the participants reading comprehension. Finally, the findings of this study suggest that teaching summarization strategy empowers students' reading comprehension ability.
\end{abstract}

Keywords: Reading comprehension strategies, Cognitive strategy, Summarization 


\section{Introduction}

Students with reading problems tend to be less aware of text structure and have poorer recall of textual ideas than good readers (Fitzgerald, 2003). Many students fail to conceptualize reading as a search for meaning, so they have a lot of problems during the study. As Ausubel (1968) claims, meaningful learning is not just some arbitrary relations among concepts in the learner's mind, but it is the fundamental process that underlies the acquisition of useful information and the construction of new knowledge. Boujaoude (1992) stated that by creating meaningful relations, learners are able to organize the information in bigger or more organized chunks of information that is an organization that reduces memory overload and increases processing capacity, ultimately improving the ability to remember information and solve problems. Moreover, the deficits in reading comprehension of many students with learning disabilities suggest the importance of teaching strategies like summarization. Furthermore, Stanley (1984) claimed that, one of the L2 readers' problems is that they may view texts as samples of language rather than information and he claimed that L2 learners studied the texts less efficiently than L1 learners, so the students may need help in achieving global understanding of that text. Moreover, one of the most important problems that readers have when they focus on every unimportant word and phrase is that not only it will decrease the comprehension of the general idea of the text, but also it is a very time-consuming process and it will decrease the speed of the learner and lead reader not to be able to read the whole text at a specific time. For example, at final examination, although students have studied very much, they cannot remember the answer very well. The reason partially refers to the student's high attention to the surface structure and their inability to make a short summarization of text, hence by observing the students focus on every unimportant details that will decrease their comprehension, we can claim that the student's reading has some problems.

Thus, this research hinges upon the idea that an understanding and awareness of some reading strategies like summarization on the part of students may provide valuable insights into the processes of language teaching and learning.

\section{Literature Review}

\subsection{Language Learning Strategies}

The differential success of second language learners suggests a need to examine in detail what strategies successful language learners employ.

According to Cohen (1998), the major part of research on language learning strategies depends on the strategies used by good language learners. Studying good language learners has proved a useful way of investigating how strategies affect language learning. Various investigations have easily produced different inventories of the learning strategies employed by good or effective language learners, with good and effective generally understood to mean those who perform well on tests or examinations or are rated as such by their teachers (e.g., Oxford \& Nyikos, 1989). 
One of the most elaborated and detailed categorization of language learning strategies has been provided by Oxford (1990) in her book Language learning strategies. Oxford sees the aim of language learning strategies as being oriented towards the development of communicative competence, and that they must, therefore, involve interaction among learners. Learning strategies must both help learners to participate in communication and to build up their language system.

In addition, it is reliable and valid across many culture groups, and it links individual strategies as well as groups of strategies, with each of the four language skill areas of listening, reading, speaking and writing (Oxford \& Burry-Stock, 1995).

In Oxford (1990), a new taxonomy is presented that a general distinction is drawn between direct and indirect strategies. The former consists of 'strategies that directly involve the target language' in the sense that they require mental processing of the language, while the latter provides indirect support for language learning through focusing, planning, evaluating, seeking opportunities, controlling anxiety, increasing cooperation and empathy and other means. Direct and indirect strategies are divided into some subcategories. Each subcategory is broken down into two further levels.

The Direct class is composed of memory strategies for remembering and retrieving new information, cognitive strategies for using the language despite knowledge gaps.

The second major strategy class, indirect strategies for general management of learning, is made up of metacognitive strategies for coordinating the learning process, affective strategies for regulating emotions, and social strategies for learning with others.

In the framework by Chamot and O'Malley (1987), three major types of strategies are distinguished in accordance with the information-processing model on which their research is based. These strategies are cognitive, meta-cognitive and social/affective strategies.

Cognitive strategies enable the learners to manipulate the language material in direct ways, i.e. through reasoning, analysis, note-taking, summarizing, synthesizing, outlining, recognizing information to develop stronger schemas, knowledge structure, practicing in naturalistic settings, and practicing structures and formulas (Celce-Murcia, 1996). That requires direct analysis, transformation or synthesis of learning materials (Rubin, 1987).

Metacognitive strategies allow the learner to control their own cognition by coordinating the planning, organizing, and evaluating of the learning process (Bruen, 2001). Purpura (1999) found that metacognitive strategies had "a significant, positive, direct effect on cognitive strategy use, providing clear evidence that metacognitive strategy use has an executive function over cognitive strategy use in task completion" (p. 61).

\subsubsection{Summarizing as a Cognitive Strategy}

It is generally agreed that well-developed reading comprehension ability is the key to the students' academic success. The comprehension ability is an active mental process. Resnick (1984) points out that, it is a process in which one "uses external information" to construct new knowledge. If the process is to occur, comprehension involves a complicated 
combination of skills in which students utilize their understanding of various elements, the how of finding main ideas and details make distinction between the two. By considering various comprehension aspects, readers must cope with the problem of specifying the best method for the purpose of contributing to its development. Some might suppose that summarization, as a kind of reading strategies, would be an effective strategy to the progress of comprehension process. According to Farstrup (2002), summarizing is a reading comprehension task that involves taking larger selections of text and reducing them to their bare essentials. It encompasses understanding the key points or main ideas of what is being read. For many students, this proves to be a difficult task. Many students require lots of instruction and practice in this skill. To effectively teach the skill of summarizing, the teacher must be prepared to model frequently and provide students with ample practice time with appropriate feedback.

A summary is a brief statement or set of statements used to show how a reader has condensed information to get to the central message of a larger chunk of information. Sometimes this central message is called the gist of the text. A summarization strategy is a set of steps that a student follows to determine the gist of the chunk of information that is being summarized. Different summarization strategies may be required for different types of text and different lengths of text.

MacArthur, Graham, and Fitzgerald (2006) describe summarization as a way to facilitate topic understanding because writing a summary allows students to manipulate information in a more active way during the reading of the text. Moreover, summarization involves teaching students step by step guidelines for creating their own summaries; students who do not learn this valuable technique would be at a disadvantage when reading content area texts. Interest in training students to summarize texts has increased both as a result of research in the skills involved in studying and learning from text, and as a result of research in the use of such training to overcome comprehension deficits in poor readers (Anderson \& Armbruster, 1982).

Summarization training has been found to improve written summaries, and also to transfer its effects to measures of reading comprehension.

\subsubsection{The Effect of Summarization on Comprehension}

Summarization is an intervention for teachers and has been demonstrated to improve reading comprehension (Pearson \& Fielding, 1991).

Readers engage in comprehension process by constructing a text-based representation of the selection they are reading as far as the relationship between summarization and comprehension is concerned. Summarizing cultivates active reading and minimizes passive reading, which influences comprehension (Rinehat, Stahl \& Erickson, 1986).

Pearson and Fielding (1991) state that active readers are involved in processing and manipulating information, using their schema or mental semantic network to organize the incoming information, retrieve the stored information and focus attention on key concepts. Moreover, summarizing allows students to become successful at reading comprehension. 
According to Chastain (1988), post-reading activities help readers to clarify any unclear meaning where the focus is on the meaning not on summarization as a kind of post-reading activity where the readers are asked to summarize the content in a sentence or two. It is also possible to give this post-reading activity in the mother tongue. Karakas (2002) proposes that the readers interpret the text and illustrate the relationship between the questions and their answers by using activities such as summarizing, question and answer, and drawing conclusions and it is possible to catch the missing parts of the mental picture through thinking aloud, discussion and summarizing.

According to Wittrock and Alesandrini (1990), summarizing allows readers to differentiate key ideas from supporting or unimportant ideas and to construct logical connections between them. Summarizing is considered as an activity that allows orderly memory search from a mental semantic network, help readers impose a structure of organization on what appears to be disassociated facts and help them retrieve information from their mental network.

Very few students are proficient at summarizing all the materials they encounter. College students frequently struggle to summarize material in their courses. Many students have not developed comprehension strategies required to condense what they have read into manageable chunks of information. Summarization requires a reader to distinguish between important, less important and trivial information and to make a judgment about what the main ideas and supporting details of the paragraph and topic levels. Judgments about importance are often based on the background knowledge of reader. As students encounter text in different areas, they need an approach to sort information and they need to see how individuals with sufficient background knowledge identify important information and summarize it. Asking student to read and summarize reading selections without the teacher's describing and routinely modeling how to use an appropriate summarization strategy especially of varying text length, content area, and complexity, will not improve the students' summarization ability. However, since almost all learning in school requires a student condense and remember what has been read, summarization comprehension strategies are important to teach.

\subsection{Reading Comprehension}

Reading is a complex process including a combination of perceptual, psycholinguistic and cognitive abilities (Adam, 1990). Furthermore, reading is interactive between reader and text. It requires sufficient knowledge of language, and sufficient knowledge of the word and a given topic (Grabe, 1997). During the 1970s and 1980s, Smith (1979) Claimed that reading would not be a linear process but the one in which readers might constantly form hypothesis, test predictions, and use their knowledge of word and of the language to construct meaning. It is widely accepted that the three key components of reading are accuracy, fluency and comprehension (Cummins, 2007).

Defining reading comprehension may not be an easy task since a lot of cognitive processes are involved in the process of reading. Johnston (1983) sees reading comprehension as the process of using the cues provided by the author and one's previous knowledge to infer the author's meaning. However, a lot more is involved in reading comprehension than inferencing, 
as various other authors conceptualize reading comprehension not in terms of just inferencing but other skills.

In addition, reading comprehension is a complex cognitive ability requiring the capacity to integrate text information with the prior knowledge of the reader, resulting in the elaboration of a mental representation (Anderson \& Pearson, 1984). Thus, reading comprehension is an interactive process that takes place between a reader and a text. During this interaction, the reader brings variable levels of experiences and skills, which include language skills, cognitive resources and world knowledge. In reading, especially in reading comprehension, readers have been found to employ a wide range of strategies, while they are engaged in comprehending text, since reading comprehension involves conscious and unconscious use of various strategies, including problem solving strategies to build a model of meaning (Johnston, 1983).

Reading comprehension is a process consisting of the simultaneous extraction and construction of meaning through interaction and involvement with written language and consists of three essential elements: a) the text; b) the function of the text, and c) the reader's capacities, abilities, knowledge, and experience with the act of reading (Snow, 2002). Unfortunately, many students require instruction on additional reading skills necessary to enhance their ability to comprehend text. According to Eilers and Pinkley (2006), comprehension strategy instruction provides a framework by which students to become aware of how effective they comprehend text and over time, enable the students experience reading difficulties to be an independent reader. Furthermore, the employed meta-cognitive strategies to improve the reading comprehension, so they find out that: a)using prior knowledge to make text connections; b) using context clues to make predictions, and sequencing of story events are necessary at meta-cognitive strategy.

There are many other variables affecting the learners' reading comprehension and plethora of experimental studies have investigated this effect in classroom settings: gender (Kaylani, 1996; Vandergrift, 1997; El-Dib, 2004), proficiency (Anderson, 2005; Bruen, 2001; Khaldieh, 2000), culture and context (Wharton, 2000), motivation (Bacon \& Finnemann, 1990; Oxford \& Ehrman, 1993; Oxford \& Nyikos, 1989; Tamada, 1996), age (Oxford, 1989; Singleton, 1989; Magogwe \& Oliver, 2007), tolerance of ambiguity (Norton, 1975; Ely, 1989), personality (Budner, 1962; Ehrman and Oxford, 1990), and self-esteem (Richard \& Schmidt, 2002).

\subsection{The Effects of Summarization Training}

Summarizing strategy training is especially effective as it has transfer effects on a variety of measures such as standardized measures of reading comprehension. There are several factors that may pave the way of these transfer effects to happen. First, summarization training makes children more aware of the structure of ideas within text and of how individual separate ideas relate to each other (Baumann, 1984). Second, summarization training encourages students to attend to text and improved meta-cognitive control of the reading processes. This is especially important for poor readers since they tend to be less attentive than good readers (Pressley, 2000). Finally, summarization required students to use other 
cognitive strategies which are necessary to good comprehension such as questioning, predicting, rereading, verifying, and activation of prior knowledge (Brown \& Day, 1983).

Brown and Day (1983) point out two tests of macro-rules for producing summaries, especially written summaries. These rules consisted of 6 rules including (1) delete unnecessary information; (2) delete redundant information; (3) compose a word to replace a list of items; (4) compose a word to replace the individual parts of action, (5) select a topic sentence; and (6) invent a topic sentence if one is not available. Furthermore, they state that summarization operations were directly taught. There were:

1. Identifying / selecting main information

2. Deleting trivial information

3. Deleting redundant information

4. Relating main and important supporting information.

Some students can read and summarize texts fairly well. However, as text becomes more difficult, increase in length, is more inconsiderate, or the student does not have sufficient background knowledge, comprehension will falter and more deliberately work on summarizing is required. Struggling readers may need instruction and practice in summarizing paragraphs; other students may need instruction and practice in summarizing larger chunks of information. However, if the material becomes more difficult to comprehend, students who previously could summarize multi-paragraph sections may need to return to more paragraph level summarizing and workup to section the summary and summary of whole chapter.

There are several ways of thinking about the types of summarization strategies. One way of thinking about the types of summarization strategies that you might teach in the classroom is by the length of text you want students to understand.

The paragraph summarization strategy: This strategy focuses on students reading one paragraph at a time, stopping at the end of each paragraph, and then asking some questions to find the main idea and supporting details. Students can tell someone what they think the paragraph is about, or they can write it.

The section summarization strategy: This strategy focuses on students reading a multi-paragraph section that covers a topic. The students begin by raising questions about what the section might be about. As the students read, they are prompted to make one important summary statement about each paragraph; at the end, they answer the questions they raised as the beginning of the section, state or write a connected summary using the important statement recorded during reading, and describe how this section relates to the preceding and following sections. The emphasis of this level of instruction and practice is on the integration on multiple main ideas to identify the significance of the set of ideas as a whole. If the student has difficulty making paragraph level important statements as part of section summarization, the students is not ready for section summarization; more instruction and practice in paragraph summarization should be provided. 
The Multi-Section summarization strategy: This strategy focuses on the type of summarization that is required for report writing. As the student reads each section in a chapter or chapter of a book, he/she makes at least three summarizing important statements. This may not cover all the information in the section or chapter, but it should be enough to help the student remember what the section or chapter was about when the summary report needs to be written. If the report is based on chapters in narrative text, the statement might focus on what happened at the beginning, middle, or end of the chapter. When the student has finished reading the text, a summary is created using the three important statements. A paragraph with a topic sentence, at least three supporting sentences, and a closing sentence are created. If the student has trouble with summarizing for report writing, then more instruction and practice in section summarization is provided.

According to Jones (2006), summarizing is one of the most important comprehension skills students need to acquire in order to become successful readers. As a result, summarizing is the ability to strip away all extraneous information to get the main idea of what you are reading. When you ask students to summarize what they have read, students will first list everything they have read. Students find summarizing very difficult at first because they are unskilled in identifying the main idea. Identifying the main idea is a complex cognitive skill that requires students to make a judgment regarding essential and nonessential information. Most often students tend to write too much or not enough. Once students understand how to pull out just the important ideas, they are able to get the gist of what they have read.

Like most reading comprehension skills, summarizing is a very difficult skill for students to learn because it is difficult to get the idea across that they don't need all the information that they read but just the important details. That said, reality is that as teachers we ask students to summarize all the time, but we rarely equip them with the skills to complete this seemingly complex task. As educators, we need to remember that we cannot expect students to do something correctly without the knowledge of the task.

Hence, Kragler (2005) points out that summarizing is a complex task for students because of several reasons. First, being the complexity of the task at hand, it involves higher level processing skills. It is not a skill that teachers can model at once and students will be able to complete. Summarizing is a skill that should never be left to be forgotten; it is a skill that must be taught in every area. Moreover, summarizing is something that students are engaged in every day and in every content area (Fortenberry, 2006).

\section{Methodology}

\subsection{Participants}

The population at the time of study contained 80 English students that they were selected from Azad University in Tonekabon. 60 of these participants were selected based on their proficiency test scores.

The students were both male and female and their ages ranged from 18 to 26 . All the 
participants majored at English language and they were divided into two groups of experimental and control each with 30 students. Both of these groups were almost equal regarding their general reading comprehension ability at the beginning of the study.

\subsection{Instrumentation}

According to the purpose of the study, a number of instruments were employed for collecting the relevant data. A proficiency test was given to the students of both groups to check their language levels and to meet the homogeneity of the participants. The Longman TOEFL test was conducted for this purpose. Also some reading comprehension tests, as a pretest and posttest, were given to the students of both groups to assess their reading comprehension ability at the beginning and at the end of the instruction and the treatment.

\subsection{Procedure}

The data collection was completed in three phases. First, the proficiency test was administered to 80 English language learners. The total score of this exam was set at 40.60 students whose obtained scores were between 25-38 were selected for the study. As discussed above, there were generally 2 groups of participants in the present study that each group consists of 30 students (15 males and 15 females). One group was randomly selected as the experimental group and another as the control group.

At the second stage, all the students were provided with a reading comprehension test selected from their course book.

The treatment sessions were held in the next procedure within a few sessions. In these sessions, students were taught how to summarize a text based on some important principles. These instructional principles, which implemented in this study, help all of the students to learn the summarization strategy well. This mode includes 4 instructional phases:

First, the researcher defined a summary as important information from a reading and stated that writing a summary is useful when one reads and studies. The researcher then described how to write down only the important ideas, while describing those that are not important or redundant.

Second, the researcher modeled and practiced the strategy for students. In this phase the researcher attempted to make the employed process explicit in applying the skill to the text. In this phase the researcher attempted to explicate the steps involved in producing appropriate paragraph summaries and gave the students additional practice in writing summaries of a single paragraph.

Third, the students practiced summarization strategy taught with short and familiar contexts which were clarified for them by instruction.

Forth, after the students had mastered the task of developing summaries of single paragraphs, they were given instruction directed towards extending that skill to groups of related paragraphs.

When the treatment was given to experimental group, the post-test, which consisted of a 
reading comprehension test, was given to both experimental and control groups. After the treatment sessions, which lasted for about one month, the post-test, which consisted of a reading comprehension text, was given to both experimental and control groups.

The obtained data were, then, plugged into SPSS software for further analysis. The results are presented in the subsequent sections.

\section{Data Analysis}

According to the purpose of the study, a two-way ANOVA was run to measure the effects of summarization, gender and their interaction in students' reading comprehension. What follows is the statistical account for the participants' reading comprehension performance on both experimental and control groups before and after the treatment.

\subsection{The Pretest}

Before running any experiment, the male and female participants' pre-test scores at experimental and control groups were examined for similarity of their reading test mean scores. The summary of the statistics is reported as follows.

Table 1. Descriptive statistics for reading comprehension at pre-test

\begin{tabular}{|l|l|l|l|l|l|}
\hline Group & $\mathrm{N}$ & Mean & SD & MD & Sig. \\
\hline Control & 30 & 9.87 & 2.34 & & \\
\cline { 1 - 4 } Experimental & 30 & 9.78 & 2.29 & .09 & .68 \\
\hline
\end{tabular}

As table 1 indicates, the mean score at the control and experimental groups are 9.87 and 9.78 , respectively. It suggests that the mean scores of these groups at pre-test are not significantly different from each other.

\subsection{The Posttest}

The purpose of this experiment is to determine the effect of summarization of text as a cognitive strategy on male and female students' reading comprehension. What follows is the statistical account for that.

Table 2. Descriptive statistics for effect of summarization on students' reading comprehension

\begin{tabular}{|l|l|l|l|l|l|}
\hline & Sum of squares & df & MS & F & Sig. \\
\hline Experimental and Control Group & 70.69 & 1 & 70.69 & 127.91 & .001 \\
\hline Summarization & 427.66 & 16 & 26.72 & 48.36 & .001 \\
\hline
\end{tabular}


According to table 2, the p-value of summarization on reading comprehension is .003 which is smaller than $.05(\mathrm{p}<.05)$. Hence, this result suggests that teaching summarization technique had a significant effect on students' reading comprehension.

Table 3. Descriptive statistics for the effect of gender on students' reading comprehension

\begin{tabular}{|l|l|l|l|l|l|}
\hline & Sum of squares & df & MS & F & Sig \\
\hline Experimental and Control Groups & 3.75 & 1 & 3.75 & 4.40 & .026 \\
\hline Gender & 1.35 & 1 & 1.35 & 2.14 & .034 \\
\hline Gender*Reading & .817 & 1 & .28 & 3.08 & .024 \\
\hline
\end{tabular}

Table 3 indicates that the $\mathrm{p}$-value of gender on reading comprehension is .024 which is smaller than $.05(\mathrm{p}<.05)$. Hence, this result suggests that gender had a significant effect on students' reading comprehension.

Table 4. Descriptive statistics for interaction effect of summarization and gender on students' reading comprehension

\begin{tabular}{|l|l|l|l|l|l|}
\hline & Sum of squares & df & MS & F & Sig \\
\hline Gender & .71 & 1 & .71 & 2.23 & .034 \\
\hline Summarization & 408.24 & 16 & 25.51 & 8.36 & .001 \\
\hline Gender*Summarization*Reading & 16.94 & 8 & 2.11 & 4.69 & .034 \\
\hline
\end{tabular}

To examine the interaction between summarization, gender, and the students' reading comprehension, a two-way ANOVA was run. Table 4 suggests that the p-value of the interaction of summarization and gender is .034 which is smaller than .05 ( $p<.05)$. Hence, this result indicates that the interaction between summarization and gender had a significant effect on students' reading comprehension.

Table 5. Descriptive statistics of reading for male and female at control group

\begin{tabular}{|l|l|l|l|l|l|l|}
\hline Group & Gender & $\mathrm{N}$ & Mean & SD & MD & Sig. \\
\hline Control & Female & 15 & 9.23 & 2.26 & .10 & .56 \\
\hline
\end{tabular}




\begin{tabular}{|l|l|l|l|l|l|l|}
\hline & Male & 15 & 9.13 & 2.21 & & \\
\hline
\end{tabular}

Table 5 presents the descriptive statistics for control group. As it is shown in the table, the female and male participants' mean scores are 9.23 and 9.13, respectively. These scores suggest that the difference between the mean scores of male and female participants at control group is not very much, and the p-value is .56, which is higher than .05 ( $p>.05$ ). These results indicate that students' improvement at control group was not significantly different among male and female participants.

Furthermore, the descriptive statistics was used to determine the mean and standard deviation of male and female participants at experimental group. Table 6 illustrates the results of the last part of this study.

Table 6. Descriptive statistics of reading for male and female students at experimental group

\begin{tabular}{|l|l|l|l|l|l|l|}
\hline Group & Gender & $\mathrm{N}$ & Mean & $\mathrm{SD}$ & $\mathrm{MD}$ & $\mathrm{Sig}$ \\
\hline \multirow{2}{*}{ Experimental } & Female & 15 & 11.96 & 3.54 & & \\
\cline { 2 - 6 } & Male & 15 & 10.15 & 10.15 & & \\
\hline
\end{tabular}

Table 6 indicates that there is a significant difference between the mean scores of male and female students. The male and female participants' mean scores are 10.15 and 11.96, respectively. As the table shows, female participants outperformed their male counterparts. Furthermore, the mean scores of male and female participants at the experimental group are higher than control group suggesting the positive effect of summarization on the participants' reading comprehension.

\section{Discussion and Conclusion}

This study aimed at examining the effect of teaching summarization technique, as a cognitive strategy, on the achievement of male and female students' reading comprehension.

Before the treatment, there was not a statistically significant difference between the control group and experimental group in terms of their reading comprehension ability, but at the end of the study, there was a statistically significant difference between the performances of the two groups in terms of their reading comprehension ability.

In addition, the results of this study indicated that, the effect of summarization on reading comprehension for male and female participants was clear and it also suggests that females respond better to this training procedure. When comparing students' scores before and after training for reading comprehension, both males and females showed significant improvement. Post test scores for males and females also showed significant improvement when compared 
with control group. This indicates that summarization had positive effect on reading comprehension.

The findings of this study revealed that the teaching of summarization as a reading strategy is effective in improving students reading comprehension. Furthermore, the form of summarization training used here transfers directly to both reading and studying behaviors, as earlier studies had found. According to the findings of this study the summarization training had a significant effect on the recall of major information in a studying task, but did not significantly affect recall of minor information. This finding suggests that the summarization training may have taught students to concentrate on major information and to disregard less important information. This suggestion is confirmed by the analyses involving the quality of notes taken during studying. In addition, it was also hypothesized that the summarization training may train students to be more attentive when they read, and that this greater attention in itself may lead to improved reading. This hypothesis was partially confirmed by findings that the experimental group spent significantly more time preparing for the test than control group, and by the path model's indication that the treatment also may exert its effect on recall of major information through increased preparation time. Hence, the summarization training appears to have increased the amount of attention paid specifically to major information (as reflected in subjects' notes). The attention paid to major information, in turn, may have increased both students' preparation time and their recall of major information from text.

Moreover, the summarization training used here appears to have improved subjects' ability to summarize short paragraphs, although this training also appears to have had differential effects on different types of paragraphs. The training had its strongest effects on paragraphs with the main idea stated within the paragraph; the training program did appear to improve children's' reading and studying behaviors and the results of this study provide confirmation of previous research findings concerning the important role with the reading strategy instruction plays in learners' reading comprehension. The results of this study, also lend support to the findings of several studies suggesting teaching learning strategies can be effective for developing students' proficiency level in a number of different skills (Chamot \& Küpper, 1989; O'Malley \& Chamot, 1990; Raymond, 1993; Wenden, 1992).

In this study, the experimental group received explicit instruction in reading strategy. This group had higher post-test scores compared with the control group.

The program which was designed in this study to employ direct, explicit instruction, including description, modeling, and paired as well as individual practice combined with feedback, to teach students to employ a summarizing strategy, called the "written summarization strategy", and summarizing rules to create a written paragraph summary of multiple-paragraph expository passages.

Results of this investigation which led to employing of a special program for teaching summarization skills, are supposed to be the key components of reading comprehension.

One important result which should be taken into account in this research is that the large majority of the students, whether those with high prior knowledge or low amount of this 
knowledge, were able to reduce the passages including two or three paragraphs to a single paragraph within a few sentences. They did it after they learned a paragraph strategies steps.

The increase in scores on the reading comprehension test from pre-test to post-test indicated the positive impact of summarization instruction on students' reading comprehension achievement.

Another important factor which should be taken into consideration on the part of the instructor is the amount of positive motivation which is given to the students by his/her when they are constructing summary statement. As (Change \& Huang, 1999) believes, changing belief about the self as a learner can have a profound effect on comprehension strategy instruction. Also, students' motivation to produce a summary increased when they came to believe that they were capable of acquiring strategies and when they made of those strategies to produce adequate summaries.

In addition, the use of reading strategy will influence the students' motivation. For example, if a student comes to this conclusion that the more he or she utilizes reading comprehension strategy, the better his or her reading skills will become, he/she will learn that strategy with high interest. Moreover, Tierney and Readence (2005) pointed out that teachers need to support, guide and show students how and why they use strategies helping them to understand the text, thus enhancing their reading comprehension abilities. Such kind of understanding paves the way for students to create a sense of self efficacy to gain success and a sense of competence with metacognitive strategies.

This study aimed at examining the effect of teaching one of the most important reading strategies on students' reading comprehension. It investigated some cognitive effects of this strategy on reading comprehension. The results of this study showed that providing learners with some instruction on reading comprehension strategies can facilitate their reading comprehension process.

The end goal of strategy training is to bring about learners that are independent of teacher and classrooms who can handle the process of learning on their own. Thus, incorporating language learning strategies is critical to the development of self-regulated learning (Wenden, 1998).

As Winograd and Bridge (1986) claimed, Guiding the students through the process of reading instruction of some strategies, like summarization, improves comprehension of text because it may force students to pay more attention to the text while making a summary; furthermore, they pointed out that this problem that teaching some of the important strategies not only provides the students with knowledge through which they can become more skilled readers, it also motivates them and puts them in control of their learning. In support of these statements Vandergrift (2003) points out that while the teacher initially plays a greater role, scaffolding should be gradually removed so that students do the work themselves, and the process can eventually become automatic and independent.

Awareness of learners about learning strategies is very essential. When learners become aware of the learning strategies, they become more independent and effective. Hence, before 
teaching students how to use strategies very well, teachers themselves should be trained in strategy instruction and assessment.

Griffiths (2006), reviewing all the previous and recent methods of language teaching and position of language learning strategies in each model, maintains that:

"With the exception of the monitor acquisition/learning hypotheses, language learning strategy theory operates comfortably alongside most of the contemporary language learning and teaching theories and fits easily with a wide variety of different methods and approaches" (p. 14).

\section{References}

Anderson, N. J. (2005). The role of metacognition in second language teaching and learning. ERIC Digest, 2, 3-4.

Anderson, T. H., \& Armbruster, B. B. (1982). Reader and text studying strategies. In W. White (Ed.), Reading expository material (pp. 219-242). New York: Academic Press.

Anderson, R. C., \& Pearson, P. D. (1984). A schematic-theoretic view of basic processes in reading. In P. D. Pearson (Ed.), Handbook of reading research. White Plains, NY: Longman.

Ausubel, D. (1968). Educational Psychology: A Cognitive View. New York: Holt Rinehart and Winston. http://dx.doi.org/10.1080/00461526809528961

Bacon, S. M., \& Finnemann, M. D. (1990). A study of attitudes, motives, and strategies of university foreign language students and their disposition to authentic oral and written input. The Modern Language Journal, $\quad$ 74(2), 459-472. http://dx.doi.org/10.1111/j.1540-4781.1990.tb05338.x

Baumann, J. F. (1984). The effectiveness of a direct instruction paradigm for teaching main idea comprehension. Reading Research Quarterly, 20, 93-115. http://dx.doi.org/10.2307/747654

Boujaoude, S. (1992). The relationship between students learning strategies and the change in their misunderstanding during a high school chemistry course. Journal of Research in Science Teaching, 29, 687-699. http://dx.doi.org/10.1002/tea.3660290706

Brown, A. L., \& Day, J. D. (1983). Macro-rules for summarizing texts: The development of expertise. Journal of Verbal Learning and Verbal Behavior, 22, 1-14. http://dx.doi.org/10.1016/S0022-5371(83)80002-4

Bruen, J. (2001). Strategies for success: Profiling the effective learner of German. Foreign Language Annals, 34(3), 216-225. http://dx.doi.org/10.1111/j.1944-9720.2001.tb02403.x

Budner, S. (1962). Intolerance of ambiguity as a personality variable. Journal of Personality, 30, 29-50. http://dx.doi.org/10.1111/j.1467-6494.1962.tb02303.x

Celce-Murcia, M. (1996). Teaching Pronunciation. Cambridge, UK: Cambridge University 
Press.

Chamot, A. U., \& Küpper, L. (1989). Learning strategies in foreign language instruction. Foreign Language Annals, 22(1), 13-24. http://dx.doi.org/10.1111/j.1944-9720.1989.tb03138.x

Chamot, A. U., \& O'Malley, J. M. (1987). The cognitive academic language learning approach: A bridge to the mainstream. TESOL Quarterly, 21(2), 227-249. http://dx.doi.org/10.2307/3586733

Change, S. F., \& Huang, S. C. (1999). Language learning motivation and language strategies of Taiwanese EFL students. Paper presented at the sixteen conference on English teaching and learning in the republic of China, Changhan, Taiwan.

Chastain, K. (1988). Developing Second Language Skill: Theory and Practice. Orlando: Harcourt Brace Jovanovich. PMCid:PMC280502

Cohen, A. D. (1998). Strategies in Learning and Using a Second Language. New York: Longman.

Cummins, J. (2007). Pedagogies for the poor: Realizing reading instruction for low-income students with scientifically based reading research. Educational Research, 36, 564-590. http://dx.doi.org/10.3102/0013189X07313156

Ehrman, M. E., \& Oxford, R. L. (1990). Adult language learning styles and strategies in an intensive training setting. The Modern Language Journal, 74(5), 311-327. http://dx.doi.org/10.1111/j.1540-4781.1990.tb01069.x

Eillers, L. H., \& Pinkley, C. (2006). Metacognitive strategies help students to comprehend all text. Reading Improvement, 43(1), 13-29.

El-Dib, M. A. (2004). Language learning strategies in Kuwait: links to gender, language level, and culture in a hybrid context. Foreign Language Annals, 37, 85-95. http://dx.doi.org/10.1111/j.1944-9720.2004.tb02176.x

Ely, R. (1989). Tolerance of ambiguity and use of second language strategies. Foreign Language Annals, 22, 437-445. http://dx.doi.org/10.1111/j.1944-9720.1989.tb02766.x

Farstrup, A. E. (2002). What research has to say about reading instruction. TESOL Quarterly, 51(3), 215-225.

Fitzgerald, J. (2003). Multilingual reading theory. Reading Research Quarterly, 38, 118-122.

Fortenberry, C. L. (2006). Mind magnents. The Reading Teacher, 60(4), 373-376. http://dx.doi.org/10.1598/RT.60.4.7

Grabe, W. (1997). Discourse analysis and reading instruction. In T. Miller (Ed.), Functional approaches to written text: Classroom applications (pp. 2-15). Washington, DC: USIA.

Griffiths, C. (2006). Language learning strategies: Theory and research. Language Teaching Journal, 2(1), 1-29. 
Johnston, P. H. (1983). Reading Comprehension Assessment: A Cognitive Basis. Newark, Delaware: IRA.

Jones, R. C. (2006). Reading quest: Summarizing strategies for reading comprehension. TESOL Quarterly, 8, 48-69.

Karakas, M. (2002). The effect of reading activities on ELT training teachers' comprehension of short stories. CANAKALE: Canakkale Onsekiz Mart University.

Kaylani, C. (1996). The influence of gender and motivation on EFL learning strategy use in Jordan. In R. L. Oxford (Ed.), Language learning strategies around the world: Cross-cultural perspectives (pp. 75-88). Honolulu, HI: University of Hawaii Press.

Khaldieh, S. A. (2000). Learning strategies and writing process of proficient vs. less-proficient learners of Arabic. Foreign Language Annals, 33(5), 522-533. http://dx.doi.org/10.1111/j.1944-9720.2000.tb01996.x

Kragler, S. (2005). Strategy instruction in primary content textbooks. The Reading Teacher, 59(3), 254-261. http://dx.doi.org/10.1598/RT.59.3.5

MacArthur, C., \& Graham, S., \& Fitzgerald, J. (2006). Handbook of Writing Research. New York: Gilford.

Magogwe, J. M., \& Oliver, R. (2007). The relationship between language learning strategies, proficiency, age and self-efficacy beliefs: A study of language learners in Botswana. System, 35(1), 338-352. http://dx.doi.org/10.1016/j.system.2007.01.003

Norton, R. W. (1975). Measurement of ambiguity tolerance. Journal of Personality Assessment, 39, 607-619. http://dx.doi.org/10.1207/s15327752jpa3906_11

O'Malley, J. M., \& Chamot, A. U. (1990). Language Learning Strategies. Cambridge: Cambridge University Press.

Oxford, R. L. (1990). Language Learning Strategies: What Every Teacher Should Know. New York: Newbury House.

Oxford, R. L. (1989). Use of language learning strategies: A synthesis of studies with implications of teaching training. System, 17(1), 47-235.

Oxford, R. L. \& Burry-Stock, J. A. (1995). Assessing the use of language learning strategies world wide with the ESL/EFL version of the strategy inventory for language learning. System, 23(2), 153-175.

Oxford, R. L., \& Ehrman, M. (1993). Second language research on individual differences. In W. Grabe (Ed.), Annual Review of applied Linguistics. Cambridge UK: Cambridge University Press.

Oxford, R., \& Nyikos, M. (1989). Variables affecting the choice of language learning strategies by university students. The Modern language Journal, 73(3), 291-300. http://dx.doi.org/10.1111/j.1540-4781.1989.tb06367.x 
Pearson, P. D., \& Fielding, L. (1991). Comprehension instruction. In R. Barr, M. L. Kamil, P. Mosenthal, \& P. D. Pearson (Ed.), Handbook of Reading Research (pp. 815-860). Plains, NY: Longman.

Pressley, M. (2000). What should comprehension instruction be the instruction of? In M. L. Kamil, P. B. Mosenthal, P. D. Pearson, \& R. Barr (Eds.), Handbook of Reading Research (pp. 545-561). Mahwah, NJ: Erlbaum.

Purpura, J. (1999). Investigating the effects of strategy use and second language test performance with high-and low-ability test takers: A structural equation modeling approach. Language Testing, 15(2), 333-379.

Raymond, P. M. (1993). The effects of structure strategy training on the recall of expository prose for university students reading French as a second language. The Modern Language Journal, 77(3), 445-458. http://dx.doi.org/10.1111/j.1540-4781.1993.tb01992.x

Resnick, L. B. (1984). Comparing and learning: Implications for a cognitive theory of instruction. In H. Mand, N. L. Stein \& T. Trabasso (Eds.), Learning and Comprehension of Text. Hillsdale, NJ: Erlbaum.

Richard, J. C., \& Schmidt, R. (2002). Longman Dictionary of Language Teaching and Applied Linguistics. Pearson: England.

Rinehart, S. D., \& Stahl, S. A., \& Erikson, L.G. (1986). Some effects of summarization training on reading. Reading Research Quarterly, 21(4), 422-435. http://dx.doi.org/10.2307/747614

Rubin, J. (1987). Learner strategies: Theoretical assumptions, research history and typology. The Modern Language Journal, $\quad 78(2), \quad 199-221$. http://dx.doi.org/10.1111/j.1540-4781.1994.tb02034.x

Singleton, D. (1989). Language Acquisition: The Age Factor. Clevedon, Avon: Multilingual Matters.

Smith, F. (1979). Reading without Nonsense. New York: Teaching College Press.

Snow, C. (2002). Reading for Understanding: Toward an $R \& D$ Program in Reading Comprehension. Santa Monica, CA: RAND.

Stanley, R. M. (1984). The recognition of macrostructure: A pilot study. Reading in a Foreign Language, 2, 156-168.

Tamada, Y. (1996). The relationship between Japanese learners' personal factors and their choices of language learning strategies. The Modern Language, 80(2), 120-131.

Tierney, R., \& Readence, J. (2005). Reading Strategies and Practices. Boston: Allyn \& Bacon.

Vandergrift, L. (2003). Orchestrating strategy use: Toward a model of the skilled second language listener. Language Learning, 53(3), 463-496. 
http://dx.doi.org/10.1111/1467-9922.00232

Vandergrift, L. (1997). The Comprehension strategies of second language (French) listeners: A descriptive study. Foreign Language Annals, 30(3), 387-409. http://dx.doi.org/10.1111/j.1944-9720.1997.tb02362.x

Wenden, A. L. (1998). Metacognitive knowledge and language learning. Applied Linguistics, 19(1), 515-537. http://dx.doi.org/10.1093/applin/19.4.515

Wenden, A. L. (1992). What do second language learners know about their language learning? A second look at retrospective accounts. Applied Linguistic, 7(2), 186-205. http://dx.doi.org/10.1093/applin/7.2.186

Wharton, G. (2000). Language learning strategy use of bilingual foreign language learners in Singapore. Language Learning, 50(2), 203-244. http://dx.doi.org/10.1111/0023-8333.00117

Winograd, P. N., \& Bridge, C. A. (1986). The comprehension of important information in written prose. In J. F. Bauman (Eds.), Teaching Main Idea Comprehension (pp. 18-48). New York, DE: International Reading Association.

Wittrock, M. C., \& Alesandrini, K. (1990). Generation of summaries and analogies and analytic and holistic abilities. American Educational Research Journal, 27, 489-502. http://dx.doi.org/10.3102/00028312027003489 